\title{
LA AGENDA GLOBAL EDUCATIVA Y SU IMPACTO EN LA EQUIDAD: EL CASO DE ESPAÑA'
}

\author{
Carmen Rodríguez-Martínez (Universidad de Málaga)*
}

\begin{abstract}
RESUMEN
La Agenda Global Educativa (AGE) actúa con reformas educativas instrumentales que están conduciendo a la convergencia de políticas educativas a nivel mundial. Sin cuestionar la hegemonía compartida entre la Agenda Global y los estado-nación nuestro interés se centra en analizar documentos oficiales y gubernamentales que tienen una influencia importante en Europa y América Latina (CUE, ONU, OEI, BM, CEPAL y OECD), contrastado con su influencia en las políticas educativas en España. Nuestro análisis se desarrolla en tres focos: los objetivos que plantea la AGE para conseguir la calidad educativa y la equidad, la traducción de estos objetivos en políticas educativas que atienden a un denominador común y las consecuencias de estas políticas educativas para la equidad. Algunas de las conclusiones apuntan que, existe una confianza desmedida en la educación para invertir la desigualdad económica y social, a la vez que ofrecen instrumentos cuantificables que proporcionan a gestores y políticos un supuesto control sobre la educación. Sin embargo, con los datos de informes y evaluaciones sobre los sistemas educativos las consecuencias de estas políticas educativas son un aumento de la desigualdad escolar y un empeoramiento de las condiciones de trabajo del profesorado.
\end{abstract}

Palabras clave: Agenda Global Educativa. Equidad. Calidad educativa. Políticas mercantilistas. Trabajo docente.

\section{RESUMO}

\section{A AGENDA EDUCATIVA GLOBAL E SEU IMPACTO NA EQUIDADE: O CASO DA ESPANHA}

AAgenda Global de Educação (AGE) atua com reformas educacionais instrumentais que estão levando à convergência das políticas educacionais em todo o mundo. Sem questionar a hegemonia partilhada entre a Agenda Global e o Estado-Nação, nosso interesse incidiu sobre a análise de documentos oficiais e governamentais que têm uma grande influência sobre a Europa e América Latina (CUE, ONU, OEI, WB, CEPAL e OECD), em contraste com sua influência nas políticas educacionais na Espanha. Nossa análise é desenvolvida em três áreas: os objetivos colocados pela AGE para alcançar a qualidade do ensino e da equidade; a tradução dos mesmos nas políticas educacionais que servem a um denominador comum; e as consequências dessas políticas educacionais para a equidade. Algumas das conclusões sugerem

1 Este estudio se ha realizado dentro del proyecto: “As políticas de educação e a reestruturação da profissão docente confrontadas aos desafios da globalização". Financiado por Fundação de Amparo à Pesquisa do Estado da Bahia (FAPESB), Brasil y dirigido por Elizeu Clementino de Souza.

* Titular de Universidad en Didáctica y Organización Escolar de la Facultad de Ciencias de la Educación, Campus de Teatinos (Universidad de Málaga - España). Grupo de pesquisa Innovación y evaluación educativa en Andalucía (Universidad de Málaga). E-mail: carmenrodri@uma.es 
que há uma confiança desproporcional na educação para reverter a desigualdade econômica e social, ao mesmo tempo em que oferecem instrumentos quantificáveis que proporcionam aos gerentes e políticos um controle assumido sobre a educação. No entanto, com os dados de relatórios e avaliações sobre sistemas educacionais, as consequências dessas políticas educacionais são o aumento da desigualdade na escola e o agravamento das condições de trabalho dos professores.

Palavras-chave: Agenda Educativa Global. Equidade. Qualidade educativa. Políticas mercantis. Trabalho docente.

\section{ABSTRACT \\ THE GLOBAL EDUCATION AGENDA AND ITS IMPACT ON EQUITY: THE SPANISH CASE STUDY}

The Global Education Agenda (GEA) acts with instrumental educational reforms that are leading to the convergence of education policies worldwide. Without questioning the shared hegemony between the global agenda and nation-states, our interest is focused on analysing official and government documents that have a significant influence in Europe and Latin America (CUE, UN, OEI, WB, ECLAC and OECD), contrasted with its influence on educational policies in Spain. Our analysis concentrates on three main areas: the objectives set out by the GEA to achieve education quality and equity, the translation of these objectives into education policies that address a common denominator, and the consequences of these education policies for equity. Some of the conclusions suggest that there is disproportionate trust in the role of education in reversing economic and social inequality, while offering quantifiable instruments that provide managers and politicians with supposed control over education. However, with data from reports on and assessments of education systems, the consequences of these education policies are an increase in school inequality and a worsening of teachers' working conditions.

Keywords: Global education agenda. Equity. Education quality. Mercantilist policies. Teaching.

\section{Los objetivos de la agenda global y su influencia en la calidad y la equidad}

La globalización está afectando a prácticas educativas nacionales y existe una influencia contrastada de diferentes organismos supranacionales en las políticas y prácticas de educación. La idea de una Agenda Global Educativa (AGE) estructurada significaría asumir la globalización como un proceso inevitable de homogeneización cultural que volvería obsoletos a los Estados-nación (DALE, 2004).

$\mathrm{Ni}$ todos los organismos internacionales plantean las mismas ideas, ni todos los países las asumen de la misma forma, aunque organizaciones como la Unesco, la OECD, y el Banco Mundial tienen una influencia universal en la instituciona- lización de ideologías, estructuras y prácticas globales actuando como representantes de los valores globales y de la política mundial en educación.

Los procesos de globalización, aunque se extienden en los documentos oficiales y gubernamentales, no dejan de tener resistencias para lograr la transformación de los sistemas educativos nacionales y los cambios no se plantean en todos como consecuencia de la influencia internacional (DE SOUZA, 2016).

Tanto Oliveira (2005) como Gorostiaga y Tello (2011) consideran que en América Latina hay una influencia de los organismos internacionales sobre las políticas educativas junto a elementos estructurales propios de cada país. Los países se están viendo forzados a aceptar la influencia de instancias internacionales que les limitan, sin abdicar completamente de su hegemonía y articulando diferentes 
propuestas en sus sistemas educativos que suponen una mayor convergencia de las políticas educativas regionales (en este caso en América Latina).

Desde perspectivas teóricas que están lideradas por autores como Stephen Ball se ha planteado el rol que juegan las escuelas y sus docentes en la producción de políticas educativas (BALL, 1993; BALL; MAGUIRE; BRAUN, 2012), la idea es "que las escuelas hacen las políticas y las políticas hacen las escuelas" (MAGUIRE; BRAUN, 2012, p. 19), dando un mayor relieve al contexto de la práctica educativa, tanto a su materialidad, historia y relaciones de poder, como a la creatividad de sus actores. Sin olvidar que el análisis de las políticas educativas globales contribuye a una ampliación del nivel de abstracción que nos permite apreciar los fundamentos sociales, económicos, políticos y educativos a partir de su puesta en práctica, la lógica de intervención y los mecanismos generales que orientan estas políticas (DALE, 2010).

Nuestro análisis se centra en analizar documentos oficiales y gubernamentales (CUE, ONU, OEI, BM, CEPAL y OECD), así como académicos, que tienen una clara influencia en Europa y América Latina, contrastando su influencia con las políticas educativas en España. Analizar, conocer y mostrar cuales son algunos de los objetivos que plantea la AGE para conseguir la calidad educativa y la equidad, y cómo se traducen en políticas y prácticas educativas.

La investigación sobre políticas educativas requiere una comprensión amplia que haga posible el debate internacional desde el análisis empírico de las actuaciones políticas a la reflexión y comprensión sobre los cambios en el papel del Estado, las relaciones entre lo público y lo privado, el papel de las redes sociales y políticas, los procesos de globalización, los cambios en el mundo del trabajo y las consecuencias de las políticas para las clases sociales y la democracia.

Empezamos por analizar algunos de los objetivos que se repiten con mayor frecuencia en los organismos internacionales sobre educación como son: mejorar de la calidad educativa, el profesorado clave de la mejora escolar y la apuesta desmedida por la educación, con el objetivo de comprender su traducción en políticas educativas y, finalmente, su impacto en la equidad.

\section{Primer objetivo: mejorar la calidad educativa}

En el Foro Mundial de la educación celebrado en Dakar en el año 2000 se incluíra dentro de los seis objetivos a conseguir en educación, Mejorar la Calidad de la educación, que define de la siguiente forma: "Mejorar todos los aspectos cualitativos de la educación, garantizando los parámetros más elevados, para conseguir resultados de aprendizajes reconocidos y mensurables, especialmente en lectura, escritura, aritmética y competencias prácticas" (ORGANIZACIÓN DE LAS NACIONES UNIDAS PARA LA EDUCACIÓN, LA CIENCIA Y LA CULTURA, 2000, p. 36)

Se plantean como una de sus metas las políticas basadas en resultados y las competencias básicas como los conocimientos esenciales para el aprendizaje del alumnado en los planes de estudio.

Los parámetros o indicadores a los que se refieren coinciden para diferentes organismos y por ello podemos decir que se conforma una agenda educativa global. Con documentos emanados de Organismos como el Consejo de Educación de la Unión Europa (UNIÓN EUROPEA, 2015), con los documentos Educación y Formación, ET, 2010, 2020 (UNIÓN EUROPEA, 2004, 2009), los objetivos del Desarrollo del Milenio de La Organización de Naciones Unidas (ONU) para 2015 y El programa Metas educativas 2021 que establece los objetivos de la Organización de los Estados Iberoamericanos (ORGANIZACIÓN DE ESTADOS IBEROAMERICANOS, 2010). El objetivo común es que las regiones puedan competir con el mundo globalizado, compartiendo la apuesta por la calidad educativa, elevando las competencias básicas de todo el alumnado y universalizando las evaluaciones con currículos orientados a la adquisición de las mismas.

La opción que asume el Consejo de la Unión Europea $^{2}$ (CUE) de una educación mercantilista, basada en la eficacia de los rendimientos, en la comparación y estandarización, es una opción neoliberal, hacia la que empujan organismos internacionales y regionales, como la OECD, el BM y la CEPAL, y que sin duda no significa un aumento de la equidad. España (país de la Unión Europea) con

2 Es una institución que representa a los gobiernos de los estados miembros. 
la Ley Orgánica para la Mejora de la Calidad Educativa (ESPAÑA, 2013) aprobada por un gobierno conservador, intensificará incluso los procesos demandados por el CUE y propondrá privatización, estandarización, selección y competitividad.

El Banco Mundial (1999) va a ser el mayor exponente de una posición economicista para América Latina y el Caribe, proponiendo objetivos muy similares al Consejo de Educación (CE) europeo, destacando la necesidad del desarrollo de capital humano. Conseguir una formación y capacitación flexible para el crecimiento económico sería el objetivo prioritario para lograr también los objetivos de cohesión social y reducción de las desigualdades y pobreza. Para ello utiliza también la inevitable comparación del rendimiento educativo entre la región y los países de la OECD (GOROSTIAGA; TELLO, 2011) que, ante unos resultados bajos, convierte en necesaria la asunción de estas políticas, igual que ocurre en el caso de España y de países del sur y centro de Europa.

Este discurso sobre la Calidad vuelve a repetirse en organismos que también defenderán el respeto a la identidad cultural, como CEPAL y Unesco (COMISIÓN ECONÓMICA PARA AMÉRICA LATINA; ORGANIZACIÓN DE LAS NACIONES UNIDAS PARA LA EDUCACIÓN, LA CIENCIA Y LA CULTURA, 1992, 2005) que intentan diferenciarse de una aproximación puramente economicista y critican las propuestas de privatización por parte de los organismos multilaterales de crédito. Pero defenderán que para la gobernabilidad del sistema educativo se requiere: mejorar la gestión, evaluar resultados de aprendizaje, descentralización territorial, democracia escolar y continuidad de las políticas (GOROSTIAGA; TELLO, 2011).

En los últimos años se suma a la calidad el reto de la igualdad. El surgimiento de sistemas educativos de "calidad e igualdad" podría ser percibido como una preocupación "global". De hecho, en la última década muchas iniciativas políticas han sido desarrolladas para ocuparse del reto de mejorar los niveles educativos para conseguir la igualdad: orientándose a la mejora de los resultados de estudiantes y escuelas en situación de desventaja, persiguiendo el desarrollo de programas de educación temprana; o enfrentándose a políticas, diseños organizativos y prácticas educativas que "dificultan la igualdad" (ORGANISATION FOR ECONOMIC CO-OPERATION AND DEVELOPMENT, 2015).

Además, durante los últimos quince años el surgimiento de "calidad e igualdad" ha sido un tema dirigido no sólo a nivel de políticas nacionales, sino también a nivel macro-regional. Tal presencia "generalizada" revela que estas políticas están influenciadas por una gobernanza transnacional y, particularmente, por organizaciones internacionales (OI), tales como la OECD o el Banco Mundial, que utilizarán evaluaciones comparadas para su consecución, junto a conocimientos estandarizados, aplicados en función del mercado laboral.

\section{Segundo objetivo: el profesorado clave de la mejora escolar}

El profesorado ocupa un lugar relevante en las agendas educativas de la Comunidad Europea y los Estados Iberoamericanos como uno de los elementos clave a la hora de introducir políticas educativas que mejoren la educación y los logros de los estudiantes. Como mencionan Monarca y Manso (2015) la confianza en el profesorado como motor de los cambios necesarios es un recurso ampliamente empleado por gobiernos y organismos internacionales, en general asociado a fuertes críticas al funcionamiento de los sistemas educativos. Se ha vinculado así, de diversas maneras y desde diversos enfoques, la mejora y la calidad de la educación con el profesorado y su formación; muchas veces estableciendo una relación directa y simplista entre calidad, formación y los resultados de los estudiantes. Los docentes aparecen entonces ubicados en un ambiguo lugar entre su responsabilidad en los resultados del sistema educativo y su imprescindible protagonismo para poder cambiarlo (ALLIAUD, 2009; FALUS; GOLDBERG, 2011; TERIGI, 2012).

Los discursos y políticas centradas en la Formación Docente se instalan en un complejo contexto cuyos rasgos trascienden a los estados nacionales. En este marco se está produciendo una gran cantidad y variedad de discursos y políticas orientadas al Desarrollo Profesional Docente (DPD) (MARCELO, 2011), aunque coinciden diversos autores y organismos nacionales e internacionales en algunos aspectos. 
Demandan un sistema de acceso que seleccione a los mejores y un desarrollo profesional que premie y distinga las "buenas prácticas". La profesionalidad docente queda definida a través de la evaluación y la formación y para ello solo tenemos que observar informes como Talis (ORGANISATION FOR ECONOMIC CO-OPERATION AND DEVELOPMENT, 2009, 2013), Barber y Mourshed (2008), Mourshed, Chijioke y Barber (2012), European Union (2013) y Organisation for Economic Co-operation and Development (2015). Para estos informes los profesores de alta calidad son clave para la mejora escolar que a su vez requiere de políticas que se preocupen por la forma en que los sistemas educativos contratan, desarrollan y mantienen a estos profesores y profesoras.

Las nuevas políticas que promueven en torno a los docentes y que la mayoría de los países han introducido en los últimos años tienen que ver con:

a) Definir estándares de calidad de los profesores para crear un marco de lo que se considera enseñanza de calidad (ORGANISATION FOR ECONOMIC CO-OPERATION AND DEVELOPMENT, 2015). La definición de estándares de calidad ha sido aplicada tanto por Chile, en lo que denominan el marco de la Buena enseñanza, como por Suecia que ha establecido un registro de profesores (2013) para demostrar que cumplen los estándares y siguen con su desarrollo profesional.

b) Reforzar la formación inicial. Casi la mitad de los países de la OCDE han introducido políticas en este sentido (ORGANISATION FOR ECONOMIC CO-OPERATION AND DEVELOPMENT, 2015), que se han centrado en nuevos cursos, programas o acreditación de programas para el control de la calidad. La selección del profesorado a la entrada de los programas de formación inicial ha sido una de las claves para elevar la calidad del profesorado. Se han introducido cambios en la formación inicial en Chile (2008, 2012), Francia (2013), Portugal (2014) y Suecia $(2011,2014)$.

c) Invertir en la carrera profesional. Políticas dirigidas a promover la selección de los profesores en su contratación y su desarro- llo profesional para mejorar la calidad de la educación y la satisfacción laboral. Han invertido en el desarrollo de la carrera docente en Portugal, vinculando la formación a la progresión y el desarrollo profesional (2014) e introduciendo la evaluación del profesorado (2013). Suecia ha aplicado aumentos salariales para los docentes de "alta calidad" en la educación obligatoria y secundaria superior.

En España se encuentra ahora mismo en debate la carrera docente y un nuevo modelo de formación inicial, que plantea aumentar la formación en el lugar de trabajo. Se propone, además desde un libro blanco realizado por expertos, la evaluación de los centros educativos, vinculada a la formación del profesorado y a su carrera docente. Esto se acompaña con incentivos en el incremento del salario y las posibilidades de ascenso profesional. La evaluación sobre el rendimiento del alumnado (accountability) es la que determina el grado de calidad docente y de los centros, las necesidades formativas y los consecuentes incentivos.

\section{Tercer Objetivo: la apuesta desmedida por la educación}

En el Marco estratégico Educación y Formación 2020 (UNIÓN EUROPEA, 2009) la educación es la clave para evitar los grandes problemas de la UE con respecto a la violencia extremista, hacer frente a la pobreza y la exclusión social, e integrar a inmigrantes y a personas de diferentes orígenes.

Mientras tenemos una sociedad cada vez más desigual en cuanto a riqueza, como muestra el informe de Oxfam Intermón (2017), que indica que nueve mil millonarios poseen la misma riqueza que la mitad más pobre del planeta y una de cada diez personas sobreviven con menos de dos dólares al día.

A partir de la crisis económica de 2008, Europa ha mantenido una política de cierre de fronteras, medidas de austeridad y de competitividad, mientras depositan toda la confianza en la educación para conseguir la equidad. Hace dos décadas ya denunció Oxfam Intermón (2013) la trampa que supuso la "austeridad" para América Latina, el Este 
Asiático y África Subsahariana y, actualmente, si continúan aplicando las mismas políticas, en 2020 casi el $40 \%$ de la población española estará en riesgo de exclusión (dos de cada cinco españoles serán pobres).

Las escuelas más igualitarias, al margen de declaraciones de ciudadanía europea, o del desarrollo de competencias cívicas, se desarrolla en los países más igualitarios socialmente, como han indicado autores como Dubet (2011) y Tedesco (2009). En la medida que se acrecientan las desigualdades sociales, las escuelas solo podrán aminorar, pero nunca transformar las desigualdades de origen, y con los nuevos mecanismos de segregación y mercantilización contribuirán a que la escuela reproduzca la desigualdad social.

Según López (2009), en América Latina se ha producido un descenso de las desigualdades sociales en el acceso a la escuela y la expansión se ha producido entre sectores que estaban desvinculados de los sistemas educativos (pobreza, contextos rurales...). Sin embargo, actualmente, se está produciendo una desaceleración en el nivel de escolarización por las desigualdades educativas dentro de los países y entre los países de la región. En América Latina vemos niveles de integración educativa muy altos en países como Cuba, Chile o Argentina, frente a otros con dificultades para avanzar en la universalización de primaria como Guatemala o Nicaragua, o los bajos resultados en América Central donde uno de cada tres adolescentes son analfabetos (ORGANIZACIÓN DE LAS NACIONES UNIDAS PARA LA EDUCACIÓN, LA CIENCIA Y LA CULTURA, 2008).

Para que un niño pueda permanecer en la escuela necesita tener un nivel aceptable de bienestar en su familia y que no recaigan sobre él responsabilidades ligadas a la supervivencia y al funcionamiento básico de su hogar. En América Latina solo tendrán oportunidad de insertarse en el mercado de trabajo dos tercios de la población. La consecuencia es que existen muchas personas que participan en un mercado informal, con formas precapitalistas de producción y circulación y que con la desregulación de la economía han profundizado en las desigualdades estructurales y han dejado a los sectores más desprotegidos como perdedores de un mercado competitivo (LÓPEZ, 2009).
Las desigualdades sociales se convierten en desigualdades escolares. Si observamos el origen social del alumnado des-escolarizado (ORGANIZACIÓN DE LAS NACIONES UNIDAS PARA LA EDUCACIÓN, LA CIENCIA Y LA CULTURA, 2008), mientras en los adolescentes solo el $50 \%$ es pobre, en primaria lo son la mayoría. Solo será posible la expansión de la cobertura escolar, la mejora de los resultados de aprendizaje y las políticas de renovación escolar si van acompañadas de estrategias de crecimiento económico (TEDESCO, 2009).

Pero la falta de equidad no está solo en los países más retrasados en educación. Incluso en casos como Chile, en los que mejoraron los insumos, con una buena inversión en las escuelas, modificación del currículo y aumento del salario de docentes (130\%), o en Francia donde también aumentaron la inversión y disminuyeron los alumnos por clase, los resultados no han mejorado. Es necesario saber donde se realizan las inversiones y con qué resultados.

El "nuevo capitalismo" está teniendo un impacto profundo en la sociedad por la concentración de ingresos, el aumento de la pobreza, el desempleo y la exclusión social, la fragmentación cultural y la erosión de los niveles de confianza de la democracia como sistema político. Sin equidad social no puede haber un proceso educativo exitoso y no se consigue con más evaluaciones.

En este contexto, si bien la educación es una condición necesaria para garantizar la competitividad, empleabilidad y desempeño ciudadano, existen cada vez más dificultades para generar posibilidades de empleo e ingresos decentes para toda la población y para crear un clima de confianza en las instituciones y en los actores políticos de la democracia. (TEDESCO, 2009, p. 79).

\section{La traducción de la agenda global en políticas educativas}

Sabiendo que no existe una Agenda Global estructurada, que significaría asumir un determinismo simplificador y la sumisión de las políticas locales a la misma, pero reconociendo a la vez que existen elementos comunes que van extendiendo su influencia en la educación mundial, su análisis cobra 
una dimensión importante sobre los fundamentos económicos y sociales de las políticas educativas en diversos contextos.

Los mínimos comunes denominadores que se suelen repetir en La Teoría de la Agenda Global Educativa (AGE) según De Souza (2016), y que concretan las políticas educativas en las que se traducen los objetivos antes expuestos son: 1) Una estandarización de la educación, que supone una reducción de los contenidos a matemáticas y lengua materna, y una reducción de la complejidad educativa a aquello que se puede medir con pruebas; 2) mecanismos de evaluación internacional, como PISA, e indicadores cada vez más comunes, que actúan como un neocolonialismo cultural; y 3) la incorporación de mecanismos de gestión empresarial en la educación.

La educación deja de ser un programa social para formar a la ciudadanía y crear sociedades con cohesión social y una mejor vida, para responder a las necesidades de mano de obra de un mercado regulado por el poder económico y estratificado. Aunque, como hemos visto, los documentos gubernamentales plantean ambos objetivos para la educación, la calidad educativa y la equidad, las estrategias desarrolladas no van a propiciar esta última.

Estas políticas educativas se extienden a partir de los años ochenta y sobre todo en los noventa en países latinoamericanos, y aunque la preocupación por la mejora de la educación se difunde una vez lograda la ampliación de los años de escolaridad, no ha supuesto una mejora en los resultados de aprendizaje y se han agravado las desigualdades sociales y regionales (POGGI, 2010; TENTI FANFANI, 2007).

Hay un interés central en la educación y la formación, que junto a la investigación e innovación, pretenden conseguir una economía más dinámica y competitiva, donde el referente siempre es la formación para el empleo. En documentos del Consejo de Educación (CE) de la Unión Europa se introducen conceptos como el de empleabilidad y emprendimiento, responsabilizando a las personas de su capacidad formativa y de creación de empleo para responder a las necesidades del mercado.

El fenómeno de la globalización nos obliga a cuestionar categorías tradicionales y hace que se apliquen modelos particulares, que provienen del mundo anglosajón, a reformas llevadas a cabo en nuestro país y en otros países europeos. Surgen nuevas narrativas internacionales sobre los modelos de reforma educativa e identifican las mejoras en educación y la calidad educativa, con la eficacia, la rendición de cuentas, la excelencia, la responsabilidad social y la acreditación.

Nos centramos en discursos académicos en debate sobre los que serían los aspectos centrales de las nuevas políticas educativas instrumentales que forman parte de la Agenda Global: 1) Evaluaciones internacionales; 2) estandarización de la educación y del conocimiento a través de competencias; y 3) la incorporación de mecanismos de gestión empresarial.

\subsection{Evaluaciones Internacionales, el gobierno de los datos}

La importancia y los formatos de las evaluaciones para la mejora no pueden entenderse si no se analiza el contexto de las situaciones económicas y sociales y las intenciones con las que se han configurado las políticas educativas. Esto nos ayuda a entender como van cobrando un nuevo protagonismo la evaluación curricular en el desarrollo de los sistemas educativos.

La crisis de 1970 genera un clima de desconfianza hacia determinados sectores, entre ellos la educación, porque las inversiones realizadas en este sector no tienen como consecuencia el desarrollo económico y el bienestar esperado. Desencadena por un lado, fuertes recortes económicos en los programas sociales y por otro desconfianza en el profesorado, e introducirá el movimiento de la accountability en las políticas anglosajonas (MARTÍN RODRÍGUEZ, 2010).

Se generan también el desarrollo de los modelos de "gestión de la calidad" entendidos como una mejora de los productos del sistema educativo y de su rentabilidad, lenguaje que resulta atrayente a gestores educativos, administradores y políticos que han visto un sistema de optimización de la gestión educativa, donde se sobrevaloran los instrumentos de medición para mejorar la calidad, sin cuestionar las finalidades educativas.

Esto queda atenuado porque una de las características de la cultura administrativa es el bajo nivel 
de responsabilidad por los resultados educativos, cuyo fracaso es atribuido directamente a los alumnos y alumnas. A partir de los años noventa, el discurso neoliberal también se apoya en este bajo nivel de responsabilidad de los gestores, pero con la novedad en este momento de que se atribuye el fracaso de los alumnos al mal desempeño de los docentes surgiendo los dispositivos de evaluación como un discurso amenazante para el profesorado (TEDESCO, 2016). Y, además, ligando la mejora de la educación a la información sobre los resultados y a la competencia entre escuelas como el mecanismo principal para conseguir esta mejora educativa.

Constituye un sistema de evaluación que evoluciona hacia su definición empresarial, en donde se va cambiando el interés por el producto a un interés por la satisfacción del cliente, convirtiéndose en una estrategia para la competencia (LLORENS; FUENTES, 2000). Conducirá a la competencia entre escuelas por conseguir clientes y en la definición de las necesidades por los clientes.

La mayoría de las pruebas objetivas utilizadas en las evaluaciones internacionales son pruebas de aptitudes (Pisa, Coleman, Pirls, Terce...) para hacer posible la comparación entre escuelas, comunidades y países, combinadas con preguntas de contenidos, muchas de ellas cada vez más estandarizadas. Crean una disonancia entre los planes de estudio y lo que es evaluado porque miden tanto aptitudes y logros de estudiantes que se producen en la escuela, como las características de los estudiantes que se producen en el contexto familiar (CARABAÑA, 2015).

Como indica Tedesco (2016), incluso entre los conocimientos escolares evaluados y los planes de estudio suelen existir fuertes disonancias. Buscan el mínimo común denominador de los aprendizajes realizados, convirtiéndose en evaluaciones de conocimientos estandarizadas.

En la accontability hay una mayor atención a los productos finales (output), se desarrolla un sistema clientelar sujeto a la demanda, no a las necesidades sustanciales (voucher, elección de centro...) y se introducen estrategias de financiamiento competitivo que benefician a los mejores colegios, a las familias con mayor nivel económico y a las sociedades con mayor equidad.
Supone el cambio de un estado docente, donde el estado se responsabiliza de la mayoría de las tareas de gestión, financiamiento y regulación de la educación, a un estado evaluador (NEAVE, 1980) o estado empresario (NOVOA, 2013), donde se descentraliza y privatiza la educación y para no perder el control establecen estándares y evaluaciones.

Novoa (2010) denomina a estas prácticas "gobernar sin gobierno" o cómo naturalizar las políticas educativas con datos, buenas prácticas y métodos. Los datos, la comparación y la evaluación al servicio de la transformación.

Las prioridades sobre objetivos en políticas educativas en Europa y Metas educativas en Iberoamérica se traducen en parámetros cuantitativos que indican la situación de cada país comparativamente y dirigen las acciones. Son evaluaciones de los aprendizajes, evaluaciones de diagnóstico que se orientan en muchos países hacia la medición de competencias estandarizadas.

Las Metas 2021 (ORGANIZACIÓN DE ESTADOS IBEROAMERICANOS, 2010) se desglosan en (1) indicadores y niveles de logro, conseguidos por el alumno en las competencias básicas, que serán evaluadas nacionalmente, además de participar en los sistemas de indicadores internacionales. Y para ello (2) crearán unidades estadísticas en los Ministerios de cada país en colaboración con instituciones y agencias de evaluación. El control y la regulación se asemeja bastante al modelo que utiliza el Consejo de la Unión Europea con sus informes anuales e intermedios.

Las evaluaciones dependerán de los gobiernos y organizaciones gubernamentales sin participación de la comunidad, ni de organismos políticos internos. Se convierte en una gestión de la educación tecnocrática que transmite mensajes muy explícitos sobre el modelo de escolaridad, a través del sistema de indicadores.

El diagnóstico de la realidad a través de parámetros cuantitativos tiene como objetivo intervenir en el cambio y en la política, no solo describir la realidad y se construye a través de comparaciones y soluciones técnicas y homogéneas. Se utilizan modelos de valor añadido (progreso del alumno a través del tiempo) para proponer soluciones a los problemas de mejora escolar (SANDERS, 1999 apud MARTÍN RODRÍGUEZ, 2010) y llevan, por 
ejemplo, a la OECD en sus informes Pisa a aconsejar, "atraer a profesores con talento a las clases más difíciles" y toda una serie de medidas sobre su reclutamiento y su formación (CARABAÑA, 2015, p. 213).

En conclusión, las reformas se suceden con un cambio de paradigma en los sistemas educativos, antes orientados por la inversión de recursos (input) $\mathrm{y}$ ahora por el rendimiento verificable del alumnado (output), lo que se llamó la "nueva gobernanza" y es volver a mecanismos de "caja negra" para la evolución de los sistemas educativos. Implica estándares e instrumentos de evaluación, test basados en niveles y el rediseño en todos los países del currículo, porque se considera que la individualización y la enseñanza orientada a la competencia dan mayor eficacia a la enseñanza y el aprendizaje (FEND, 2012).

\subsection{Estandarización de la educación}

Desde que las nuevas políticas educativas quieren preparar para los requerimientos de la economía nacional hay una tendencia global a la construcción de currículos centralizados, que introducen como novedad una formación en competencias y habilidades básicas en los cursos obligatorios (en matemáticas y lengua fundamentalmente) o especializada en Formación Profesional y estudios superiores.

La Estrategia de Competencias de la Organisation for Economic Co-operation and Development (2012) ha reconocido la necesidad de que los sistemas educativos garanticen que los estudiantes finalicen la educación obligatoria y que sus competencias (competencias cognitivas, interpersonales y de alto nivel en general) respondan a las necesidades del mercado laboral. Esta será una línea común a la Comisión de la Unión Europea (CUE) y a la planteada en las Metas 2021 (ORGANIZACIÓN DE ESTADOS IBEROAMERICANOS, 2010), con la relación entre educación y empleo que debe ser fomentada, en la alfabetización y en la educación a lo largo de la vida, con la máxima del "aprender a aprender" para insertarse en el mundo laboral.

Las competencias se plantean como una forma de mejora de la calidad de la educación a lo largo de la vida, siempre como una estrategia de empleo, crecimiento e inversión (mercantilista), recomendación del Parlamento Europeo y del CUE. Permiten, además, la comparación internacional de los sistemas educativos que va a estar reforzada por la universalización cada vez mayor de las evaluaciones internacionales. La evaluación de los rendimientos del alumnado serán el elemento unificador en la aplicación de reformas a nivel mundial.

En la concepción de las competencias hay una transformación desde un significado creado desde las teorías del constructivismo a un uso instrumental para el mercado que sigue creando confusión en los discursos de académicos y académicas. Las competencias se identificaban con el viejo concepto pedagógico de "aprender a aprender" que se basa en la construcción del conocimiento, pero actualmente adquieren un nuevo significado, son consecuencia de la nueva perspectiva economicista del pensamiento educacional, con la introducción de las teorías del capital humano, que medirán el valor de la educación por su contribución al crecimiento económico. Criticadas en los años sesenta (introducidas por empresas) volverán a través de las recomendaciones de agencias internacionales como la OECD y el BM, con la perspectiva de que los que no son considerados capaces de un alto rendimiento solo tienen que aprender lo "básico": una escuela que anticipa y reproduce las divisiones y jerarquías del mundo laboral (PINI, 2010).

Las competencias plantean contenidos centrados en lo básico (new basics), para conseguir habilidades y capacidades instrumentales, demandadas por informes internacionales como Pisa (OECD), Pirls (IEA), Terce (LLECE), que están reformulando los currículos de los sistemas educativos, simplificando los aprendizajes a competencias básicas instrumentales y creando un sistema educativo que responde a los designios del mercado. Ello crea una sociedad de la ignorancia (BREY, 2009), preparada en saberes instrumentales aplicables y especializada en saberes productivos, todos ellos restringidos a campos específicos y adaptados a los intereses del mercado sin cuestionar los propios marcos que los sustentan.

Saberes instrumentales que dejan atrás el acervo cultural y conducen a lo que se está denominando la "nueva cultura del capitalismo" que Tedesco (2008, 2009) y autores de diversos campos (BECK, 1998; 
GIDDENS, 2000; SENNETT, 2006) caracterizan por el corto-placismo y la lógica de la demanda construyendo un déficit de sentido que deja en la incertidumbre a la educación, como consecuencia de la fuerte concentración en el presente y la ruptura con el pasado. El conocimiento se convierte en instrumento para renovar las economías nacionales y no en algo que tiene valor en sí mismo para decidir sobre nuestro futuro. Al poner el énfasis en la programación de competencias y en su evaluación, estandarizan la enseñanza, fragmentan los contenidos y los convierten en instrumentos (datos y conceptos).

Una mejor educación y formación (cualificación y competencias) no deberá responder solo a las necesidades del mercado laboral, ni propiciará el crecimiento económico. Los defensores de la unión entre formación-educación y políticas de empleo creen que los países que dispongan de un capital humano mejor formado verán crecer sus tasas de productividad, explicación que se reitera en varios documentos de la UE, el Banco Mundial y la OECD, recogida en España por la LOMCE (ESPAÑA, 2013). Sin embargo, una mayor formación o disponer de un mayor "capital humano" no generarán más empleo a un país, como nos demuestra Hirtt (2013), aunque las personas mejor formadas tengan más posibilidad de conseguirlo. El empleo va a depender del tejido industrial desarrollado, las apuestas por la innovación y la ciencia y las inversiones de capital, que deben regularse por leyes internacionales para que no supongan el enriquecimiento sin límites de un pequeño porcentaje de la población, mientras el trabajo se degrada para hacernos más competitivos. De hecho nuestros jóvenes más preparados en España están emigrando, con investigaciones punteras y con carreras flamantes recién terminadas. ${ }^{3}$

\subsection{Privatización e incorporación de los mecanismos de gestión empresarial}

La competitividad es el corazón de estas nuevas políticas públicas de gestión (New public management) y no el intercambio libre de mercancías,

3 El FMI calcula que para 2019 en España habría alrededor de 1,5 mill. menos de personas en edad de trabajar en España. inspirado en la organización de empresas privadas, donde el principio fundamental por el que se rigen es "el más por menos": los modelos tecnocráticos de gestión demandan "más eficacia" con una "menor inversión" para que sean rentables. El problema de la educación no se soluciona con una mayor inversión económica, proclamarán, sino con una gestión eficaz que dependerá de los productos que consigamos, de la medición de los resultados y la satisfacción de las necesidades de los clientes (NAVAS QUINTERO, 2010). El Estado se convierte en vigilante de la competencia y premiará la eficacia a través de la evaluación de los rendimientos del alumnado.

El modelo privado se ajusta perfectamente a este modelo y la competitividad entre empresas garantiza la mejora de los resultados, aunque sea a costa del deterioro de las condiciones laborales del profesorado y de la calidad de los servicios. Son procesos que están sufriendo todos los servicios públicos, no porque estas políticas signifiquen un retroceso del Estado, sino porque se instaura un orden marco en el que el propio Estado se vuelve guardián del principio constituyente de la competitividad (LAVAL; DARDOT, 2010). Se demonizan las políticas de intervención del Estado en la gestión, no en la rendición de cuentas, porque suponen un obstáculo para obtener rentabilidad a corto plazo, y se refuerza la desregulación de los sectores financieros, de los medios de comunicación... hasta llegar al último negocio que son los servicios públicos (SACHS, 2012).

Cuando los servicios públicos entran en competencia entre ellos ofrecen desiguales estándares de calidad para la población. Esto es tanto más peligroso en un servicio como la educación, donde las condiciones del trabajo del profesorado y su consideración tienen mucho que ver con la calidad de todo el servicio, porque el ambiente de la escuela, los recursos, su seguridad y las características de sus estudiantes forman parte de las compensaciones de su trabajo, no son un objeto ajeno a ellos, forman parte de la educación que construyen con su alumnado (CARNOY, 2006). ${ }^{4}$

4 Históricamente los trabajos relacionados con la educación, los servicios y el cuidado tienen estas características y deberían de ser los más relevantes en las condiciones y consideración de los profesionales, pero pasa justo lo contrario por haber sido trabajos feminizados. 
Llama la atención cómo en Europa en documentos oficiales se demanda estimular las inversiones en el sistema escolar, sobre todo las vinculadas a las prioridades del programa Educación y Formación 2020 (UNIÓN EUROPEA, 2015), mientras desde Bruxelas (la Unión Europea) exigen pagar las deudas y la contención del gasto todos los años. De esta forma el gasto en educación en España ha bajado desde un 4,9\% del PIB en 2009, hasta un $3,9 \%$ y debe bajar a un 3,67\% del PIB para el año 2020, según acuerda el gobierno español del Partido Popular (derechas) con Bruxelas. ${ }^{5}$

En el informe Educación para Todos (ORGANIZACIÓN DE LAS NACIONES UNIDAS PARA LA EDUCACIÓN, LA CIENCIA Y LA CULTURA, 2015) también se informa que desde el año 2000 han aumentado los establecimientos de enseñanza privada, que logran mejores resultados probablemente porque vaya alumnado de medios sociales más favorecidos.

Como indica el informe de Verger, Moschetti y Fondevila (2017), América Latina es la región del planeta donde ha avanzado la privatización de forma más pronunciada y constante en las últimas décadas. La privatización no consiste en pasar las escuelas públicas a manos privadas, sino en una mezcla de procesos diversos de financiamiento y provisión entre agentes privados y servicios educativos que conducirán a la competencia entre escuelas y al aumento de la segregación escolar. La práctica habitual para ello es la selección del alumnado más favorecido académicamente y más disciplinado.

En España, mientras la inversión ha bajado para la educación pública, ha subido para la educación privada financiada con dinero público (concertada). Si nos fijamos en los años de la crisis desde 2009 a 2016 la financiación de la red privada-concertada (32\%) ha aumentado en 346 millones de euros, mientras que en la educación pública disminuía en 6.400 millones, especialmente en las comunidades autónomas gobernadas por el Partido Popular (Madrid, Valencia, Murcia y La Rioja) (CONFEDERACIÓN SINDICAL DE COMISIONES OBRERAS, 2018). A ello debemos añadir la disminución del número de unidades escolares públicas y la potenciación de la privada concertada en los procesos de escolarización.

5 “Actualización del programa de estabilidad 2017-2020".
Se apoyan en la creencia de que es más barato el contrato privado de servicios que antes eran suministrados por el gobierno, aunque sigan siendo financiados por el mismo, lo que se llama actualmente las alianzas público-privado (PPP en sus siglas en inglés public-private-partnerships). Estas políticas son respaldadas por organismos internacionales que apoyan el proceso de globalización económico, entre los que destaca el Banco Mundial. ${ }^{6}$ Para ello emplean fórmulas de privatización variadas: la financiación educativa a través de los cheques escolares, la externalización de servicios educativos, centros de titularidad privada pero financiados públicamente, acompañadas de medidas que redundan en la competitividad, como la publicación de resultados escolares y la eliminación de zonas escolares para facilitar la elección escolar (LUBIENSKI, 2009). Primero fueron los EEUU en los años ochenta, después Reino Unido y cada vez se implantan más en países en vías de desarrollo como India y Haití, donde el Banco Mundial ha dado enormes cantidades de dinero para proyectos educativos con las alianzas público-privadas (VERGER; BONAL, 2012).

Hoy día se llega a incluir como una obligación la financiación de centros privados en las mismas condiciones que la escuela pública, recogida tanto en leyes educativas de gobiernos (como la LOMCE en España), como en el nuevo tratado entre EEUU y Europa (TISA), que deberán responder a la demanda social (la elección de escuela de las familias), frente al derecho del niño a la igualdad y a una educación sin idearios particulares, con libertad de pensamiento, conciencia y religión. ${ }^{7}$

Es un modelo liberal-conservador que se asienta en la hipótesis de que privatizando las escuelas o sus mecanismos de gestión aumentará la eficacia. Son nuevas fórmulas de meritocracia que refuerzan la desigualdad y una escuela exclusiva que redundan en la pérdida de legitimidad de la escuela universal y pública. Una escuela que prepara para competir y que responde a las necesidades de los

6 Este organismo ha constituido el "Equipo de Expertos Global sobre PPP" y la "Red Global de PPP del Banco Mundial". Es también uno de sus temas prioritarios en la formación de técnicos y políticos.

7 Defendida en la Declaración de los Derechos del niño de 1959 y en la Convención de 1989. 
mercados como mecanismo de creación y distribución de la riqueza según el "esfuerzo" o el nivel socioeconómico.

Esta lógica competitiva y de mercado para la escuela combina con los deseos de ambientes familiares y religiosos que demandan el individualismo y la elección de centros. Ya la escuela no es una promesa de futuro laboral o de diferenciación social, al menos para todos, y las clases medias $\mathrm{y}$ altas pugnan por mantener este objetivo para los suyos.

Las familias sienten desconfianza en la educación por la masificación de los estudios de secundaria y superiores, junto a la exigencia de la economía de altos niveles de cualificación que ya no garantizan un puesto de trabajo para todo el mundo. Esta es la razón por la que buscan el "cierre social" y que sus hijos e hijas, sirviéndose de su capital cultural (información, relaciones...) y económico (posibilidades de residencia, desplazamientos, actividades suplementarias...) accedan a grupos homogéneos de élite y tengan más posibilidades de éxito (VAN ZANEN, 2008). Con la elección de centro se recubre de derecho individual lo que es una selección social buscada por clases sociales altas y medias. Una "demanda" de las familias que es debidamente teledirigida por las políticas educativas en España y normalizada por la LOMCE. Para ello se realizan políticas de recortes en el sector público, desgravaciones fiscales para quienes llevan a sus hijos a colegios de pago, cierre de aulas o unidades escolares en centros públicos, apertura de privados financiados con suelo público, contratación temporal de personal docente al margen del procedimiento público, implantación del distrito único para la admisión de alumnado, evaluaciones con fines comparativos... (VIÑAO, 2014).

Se crean procesos de segregación de las escuelas en grupos sociales y prácticas de concentración del alumnado con mayores dificultades que hace que la escuela pública universal decline su valor como institución. Se cuestiona la educación como derecho y las nuevas políticas de gestión asumen que las personas son responsables individualmente de su bienestar. Las nuevas condiciones económicas propician el nuevo modelo educativo al servicio de la economía.

\section{Conclusiones: consecuencias de las políticas educativas de la AGE contrarias a la equidad}

Algunos investigadores como Filmus (1994) han reivindicado que la calidad era la única garantía en la lucha contra la exclusión, pues la misma duración con modelos de diferente calidad harían que la educación fuera una fuente de desigualdades.

Garantizar el acceso a una formación de calidad, con el desarrollo de la igualdad, la no discriminación y las competencias cívicas, es una preocupación de los gobiernos, porque se ha comprobado que en los últimos treinta años se ha producido un gran aumento de la desigualdad, como queda recogido en la Declaración de Paris, de los ministros de educación europeos (EUROPEAN UNION, 2015).

El informe de la OECD sobre equidad (2017) indica que la desigualdad de ingresos ha crecido en la mayoría de los países desde la década de los ochenta y, aunque observa que tiene un impacto negativo en el crecimiento económico, considera que la educación puede cambiar este ciclo. Está claro que hay sistemas más equitativos que otros y alumnado que son resilientes a pesar de pertenecer a entornos socioeconómicos desfavorables, que como vimos es una apuesta desmedida por la educación.

Con la simple extensión de la educación secundaria obligatoria no es suficiente, porque aunque se considere un avance del derecho fundamental de la educación, puede convertirse en una barrera si en los centros hay una representación desigual según los niveles de renta, falta de atención educativa según necesidades (no demandas) y políticas mercantilistas en contra de la justicia social. Podemos afirmar que así ocurre y que a ello contribuye: la falta de plazas públicas (y que éstas sean de calidad), la elección de las familias, el aumento de la privatización y diferentes prácticas de segregación escolar.

En América Latina se ha logrado una mayor cobertura, pero con insuficiente calidad (COMISIÓN ECONÓMICA PARAAMÉRICA LATINA; ORGANIZACIÓN DE LAS NACIONES UNIDAS PARA LA EDUCACIÓN, LA CIENCIA Y LA CULTURA, 2005). Los esfuerzos de los países han contribuido a mejorar el acceso y permanencia 
del alumnado, en el año 2003 el 90\% de los niños y niñas de la región están cursando estudios de primaria y cerca del $70 \%$ de secundaria, si bien las tasas de permanencia son más bajas.

Se ha realizado un aumento de la escolarización sin que se haya invertido en la mejora de la escuela pública, en cuanto a los recursos, al tiempo de aprendizaje, a la situación y formación del profesorado, un currículum que sea atractivo, a la insuficiente gestión y a los bajos resultados que recogen año tras año las evaluaciones. Hay un deterioro de una escuela pública gratuita y mayoritaria que atiende al alumnado de los sectores más populares y una escuela privada minoritaria que escolariza al alumnado de la clase media alta de la población.

El modelo de justicia social ha cambiado como consecuencia del modelo global capitalista que, preocupado por la meritocracia, nos conduce a una aceptación pasiva del crecimiento de las desigualdades. En educación nos lleva a aceptar que los rendimientos escolares dependen del esfuerzo y del talento de cada estudiante y que las familias que se preocupan especialmente de la educación de sus hijos/as tienen derecho a tener mejores condiciones y escuelas. Admitimos la inevitabilidad de la reproducción social (equivalente moderno del privilegio) y que las diferencias se transmiten como destinos inexorables de generación en generación (ROSANVALLON, 2012).

Los factores que van en contra de la equidad según el informe de la Organisation for Economic Co-operation and Development (2017) son: la selección temprana de los estudiantes según sus habilidades (Austria y Alemania a los 10 años), el grado de repetición (Francia, Luxemburgo y España), no incluir estándares de aprendizaje muy elevados (varios estados de Alemania), flexibilidad en el cambio de agrupamientos de aprendizaje y desigualdades geográficas. La brecha urbana/ rural, así como las disparidades entre distritos de la misma ciudad que han hecho que se aumente la opción de las familias en la elección de centro.

Como conclusión vamos a destacar algunos elementos que caracterizan las políticas educativas de la Agenda Global y que repercuten en la falta de equidad: la reestructuración de la profesión docente, las prácticas de segregación escolar y las políticas mercantilistas y liberalizadoras.

\subsection{La reestructuración docente}

Durante las últimas décadas se han construido discursos sobre las finalidades de la educación unidas al desarrollo laboral y al fortalecimiento socio-económico de los países. Ello ha ocasionado una demanda de un marco profesional docente adaptado y postrado a una sociedad competitiva y consumista, donde el cálculo del coste-beneficio y la ideología individualista están por encima de otras finalidades educativas. Parece que la información y la formación son una mercancía preparada para consumir y los conocimientos sirven para la acreditación y la meritocracia.

Los informes de algunos organismos internacionales reiteran que "si los estudiantes no tienen buenos resultados es porque el profesorado no está bien preparado", o sea, bien formado, desplazando la responsabilidad de los contextos sociales y económicos, de las condiciones vitales del alumnado y de las propias políticas educativas. Y como no está bien formado se hacen propuestas que convierten la formación del profesorado en un incentivo para la carrera docente y la unen a la evaluación y al desempeño del alumnado, responsabilizando indebidamente al profesorado de los resultados del sistema educativo y de la desigualdad social ${ }^{8}$.

Los modelos pos-burocráticos de gestión eficaz introducidos en muchos países, también en España, cambian las prácticas escolares y significan una reconstitución de la profesión docente. $1^{\circ}$ Proletarizan la profesión docente, la preocupación por subir los niveles educativos lleva a una centralización y estandarización de los currículos con la pérdida de autonomía en el trabajo docente; $2^{\circ}$ precarizan las condiciones de empleo con la falta de estabilidad y la introducción de contrataciones; y $3^{\circ}$ precarizan las condiciones laborales con menos salarios, recursos, apoyos y más horas y número de alumnado. Las políticas sobre el profesorado se basan en la incentivación y en una mayor productividad, pero con menos recursos (políticas del más por menos). Los convierten en asalariados que ejecutan las tareas que otros deciden y devalúan su cualificación y estatus profesional. Estas políticas han sido ya aplicadas en países anglosajones y latinoamerica-

8 Libro Blanco encargado a expertos por el Partido Popular en España. 
nos, que nos sirven de referencia, para contrastarla con España.

$1^{\circ}$ Proletarizan la profesión docente. El control de la autonomía del profesorado se realiza en la LOMCE a través de las evaluaciones finales de etapa (primaria, secundaria y bachillerato) que son un instrumento en contra de las condiciones del trabajo docente porque cercena la autonomía del profesorado y su capacidad de innovación y de decisión sobre lo que deben aprender sus alumnos e incluso cómo deben hacerlo. La estandarización del currículum a través de estas pruebas convierte al profesorado en un preparador de exámenes que deba superar su alumnado para progresar a la siguiente etapa educativa. Por otro lado, al alumnado lo conducen hacia unos rendimientos que tienen que ser fácilmente evaluables, por lo que generan un aprendizaje mediocre.

Como hemos visto la eficiencia de los sistemas educativos basada en los rendimientos del alumnado responde a un modelo economicista y competitivo que creará desigualdad y aprendizajes reproductivos al basarse en item de conocimientos fácilmente evaluables y cada vez más sujetos o ceñidos a los intereses del mercado.

Las evaluaciones externas se plantean como un requisito para la mejora de la educación, como consideran desde el Instituto Nacional de Evaluación del Ministerio de Educación, Cultura y Deporte (INSTITUTO NACIONAL DE EVALUACIÓN EDUCATIVA, 2015) y en lo que han coincidido gobiernos internacionales como Chile y EEUU que llevan cierto tiempo aplicando estas políticas y otros que se van incorporando como México, Guatemala... Son escasos los países de nuestro entorno que no se sometan a evaluaciones internacionales comparativas tipo PISA, y las evaluaciones nacionales para evaluar el desempeño docente basado en rendimientos del alumnado son cada vez más frecuentes, como indica el informe Teaching and Learning International Survey - TALIS (2013).

En oposición, académicas como Ravit (2010, 2013), responsable de políticas educativas de test con Clinton y Bush, argumenta que las pruebas externas han supuesto un desgaste en la calidad de la educación en EEUU. El único valor que tienen las pruebas normalizadas es el de clasificar, calificar y repartir entre el profesorado premios y castigos.
La escuela es un instrumento básico para el desarrollo de la autonomía, la conciencia y la responsabilidad como ciudadanos y ciudadanas y para ello se requiere un profesorado que sea libre y autónomo en su relación con el conocimiento. La profesionalización y mejora de la docencia fijarán el objetivo en el alumnado y no en los intereses ideológicos de las diferentes reformas, considerándolo un profesional autónomo que tiene una proyección importante en la concepción y desarrollo del currículo, que será un aspecto propio de los debates profesionales. La estandarización del currículum y las evaluaciones externas solo sirven para regular las prácticas escolares, restar autonomía al trabajo del profesorado y después responsabilizarlo y culpabilizarlo de los resultados.

$2^{\circ}$ Precarizan las condiciones de empleo. El Banco Mundial ya recogía en 1999 que los problemas de calidad educativa se solucionarían si los maestros fueran seleccionados en términos de coste-beneficio y la responsabilidad de la contratación fuera de los equipos directivos. Este discurso parece un "mantra" repetido durante 20 años. Lo vuelve a repetir la OECD en 2012, que cuestiona el modelo funcionarial de la docencia pública española, infravalorando la experiencia del profesorado y lamentando que los directores no puedan influir en la selección del personal de los centros. Y lo resuelve la LOMCE, dando responsabilidades para contratar a los directores y directoras directamente.

El cuestionamiento de la estabilidad docente se fundamenta en la desincentivación del trabajo del profesorado, también perjudicial para conformar equipos de trabajo en las instituciones educativas. En Argentina los argumentos han sido similares, el objetivo es conseguir equipos de trabajo que compartan las mismas ideas y formas de trabajar, en concreto los mismos proyectos para conseguir escuelas exitosas (SAFOCARDA; MIGLIAVACA; JAIMOVICH, 2006). De hecho en la LOMCE la contratación se relaciona con la búsqueda de perfiles acordes al proyecto de centro, pudiendo contratar el director o directora hasta el $100 \%$ de la plantilla en los centros de nueva creación.

La figura del funcionario se crea en España en el s. XIX, para que los trabajadores y trabajadoras de la administración no fluctuaran cada vez que un nuevo partido llegaba al poder. Es consecuencia de 
un pacto entre los propios partidos para garantizar que estas personas tuvieran unos conocimientos adecuados y pudieran mantener una relación con la ética pública, como diría Weber (2002), y por este cauce, abre el horizonte del bien general, como marco de su actuación.

La estabilidad laboral en Argentina también fue reclamada desde principios del s. XX para resguardar a los docentes de los condicionamientos de políticos, religiosos o filósofos. Es reconocida como derecho en sus estatutos (nacional y provinciales), pero esto no ha servido para que se supriman, en los últimos tiempos, para suplentes o interinos. Cada vez es mayor la cantidad de años que tienen que esperar en situación precaria para alcanzar la titularidad. Se han afianzado también en educación los contratos por tiempo limitado (SAFOCARDA; MIGLIAVACA; JAIMOVICH, 2006).

$3^{\circ}$ Precarizan las condiciones laborales. La crisis fue una buena excusa para cambiar las condiciones del profesorado de todos los niveles educativos, aunque ya se habían hecho recortes con anterioridad. Con la imposición del Real Decreto-ley de abril de 2012, por el partido Popular se aumentó la carga docente, en una cifra superior a un $10 \%$, que ha significado pasar al profesorado de secundaria de 18 a 20 horas lectivas; y se aumentó el número de alumnado por clase, que ha permitido incrementar la ratio legal en un $20 \%$ subiendo el número de estudiantes por aula hasta 30 (de 25) en primaria, 36 (de 30) en secundaria y 41 (de 35) en bachillerato.

Además se fija en este RD en un $10 \%$ la tasa de reposición de profesorado que deja la enseñanza por jubilación, por abandono o fallecimiento. ${ }^{9}$ Esto ha supuesto la disminución del número de profesores y profesoras en un 20\% hasta 2013-2014, siendo en 2012-2013 el segundo sector con más pérdida de empleo después de la construcción, según la Encuesta de Población Activa.

Además las políticas de disminución del gasto público en educación pública se traducen en: una disminución del sueldo del profesorado, solo de 2010 a 2014 se reduce de un 20 a 25\% según comunidades; y la inversión en la formación del

9 Aunque en 2017 ha vuelto a ser del $100 \%$, aun no se ha recuperado el profesorado que había al principio de la crisis y el número de alumnado ha aumentado. profesorado, haciendo desaparecer los Centros del Profesorado en algunas Comunidades.

También ha significado la contratación precaria de profesorado (contratación en tiempos parciales, no han cobrado vacaciones...) sobre todo en Comunidades del Partido Popular y en casi todos las universidades.

La estabilidad, la autonomía y un status y consideración adecuados del profesorado son los únicos elementos que pueden garantizar una educación de calidad, que no sirva a los designios de los políticos y administradores. Para educar a ciudadanos y ciudadanas libres hace falta una pluralidad de visiones e independencia del poder político. La estabilidad en el puesto de trabajo garantiza la imparcialidad.

\subsection{Las prácticas de segregación escolar}

Todos los informes PISA destacan la mayor o menor equidad del sistema educativo, al comparar los resultados de aprendizaje con el origen socioeconómico. Por ejemplo, España es un sistema educativo muy equitativo porque el peso del origen socioeconómico en los resultados educativos es parecido a la media de los países de la OECD.

El índice de equidad de PISA en realidad nos dice lo que ya sabemos, que el contexto sociocultural de las familias afecta a los resultados educativos. Ello permite afirmar que la escuela pública es igual de buena que la concertada, porque si eliminamos el nivel socioeconómico del alumnado obtendrán los mismos resultados. Pero lo importante no es que tengan unos resultados similares sino que los grupos de los que forman parte frenarán su progreso.

Uno de los datos más interesantes del informe PISA, para demostrar la segregación, es el índice de inclusión social, que refleja que en la escuela conviven alumnos y alumnas plurales y diversos y cada escuela es una foto microscópica del conjunto de la sociedad. Así, los países nórdicos, Corea del Sur, Japón o Canadá tienen las escuelas más inclusivas, "donde cada escuela es un espejo de la sociedad", mientras los países latinoamericanos o del este de Europa son escuelas muy homogéneas (GORTÁZAR, 2017).

En América Latina y el Caribe, como veíamos, las cifras netas de cobertura en la educación pri- 
maria son semejantes a las de países desarrollados y la asistencia escolar en la baja secundaria se ha elevado en el año 2005 a un 94\%. El logro de estos niveles es reciente pero se aprecia una segmentación y segregación del servicio educativo, existe una clara diferenciación entre la experiencia escolar a la que acceden la mayoría y la que está reservada a las élites (ORGANIZACIÓN DE LAS NACIONES UNIDAS PARA LA EDUCACIÓN, LA CIENCIA Y LA CULTURA, 2007).

Como nos muestra García-Huidobro (2009), la segregación es evidente, los más ricos (el 59\% del cuartil más acomodado) asisten a establecimientos mejor dotados, en los que hay más recursos y separados del resto de la sociedad, sobre todo, de los más pobres (el 32\% del cuartil menos acomodado, a 27 puntos de distancia). Los resultados son que Brasil y Chile ocupan el segundo lugar después de Tailandia; y Uruguay, Colombia, Argentina y México también aparecen entre los países de mayor segregación. Uno de los factores que contribuye a esta segregación es la educación privada, que corresponde a un $17,1 \%$ de la matrícula latinoamericana en primaria y $19,3 \%$ en secundaria (PEREYRA, 2008 apud GARCÍA-HUIDOBRO, 2009), con situaciones polares como Chile donde supera la privada a la pública y Guatemala en la educación secundaria ${ }^{10}$, mientras México, Bolivia y Brasil poseen los menores porcentajes.

En España el índice de inclusión del alumnado ha pasado de 74 puntos en 2012 a 69 en 2015, ocupando la antepenúltima posición de los países de la OECD en Europa y la quinta por la cola de toda la OECD (ROGERO-GARCÍA, 2017).

En el informe de la Organisation for Economic Co-operation and Development (2017), basado en Pisa (2015), aparece que España no segrega porque no tiene itinerarios en el nivel de educación secundaria inferior (aún no aplicados, aunque están previstos en la LOMCE). Estos informes de macroestudios observan solo factores declarados y no tanto la cultura y la práctica escolar, donde España segrega a partir de otros factores: la distribución del territorio (Sur más pobre), la educación privada financiada (tercer país en Europa con un 32\%),

10 Con situaciones muy diferentes porque la privada en Chile está apoyada por el Estado y en Guatemala hay una escasa iniciativa estatal. clasificación interna en los centros de secundaria por niveles educativos, programas de bilingüismo y de Bachillerato de excelencia, que son nuevas formas de apartheid dentro de las mismas escuelas $\mathrm{y}$, finalmente, con políticas de elección de centro.

El problema, más que los rendimientos escolares, son las dificultades que se encuentran alumnos y alumnas para progresar cuando la fragmentación frena al sistema educativo en su conjunto, porque reúne a una excesiva proporción de estudiantes con dificultades económicas y académicas. Esto tendrá como consecuencia: bajas expectativas hacia los estudios, situaciones de vulnerabilidad y de bajo desempeño escolar, dificultades para el profesorado y baja motivación para el trabajo de los equipos docentes y para mantener su estabilidad en estos centros.

La segregación social disminuye la capacidad del sistema educativo para enseñar, se inhibe el efecto de los pares (con quienes se aprende) y además tienen experiencias en escuelas con menores recursos y oportunidades. Las escuelas con mezcla social son más favorables como defiende Pisa (2015). El efecto principal de obtener menores logros educativos no proviene del origen social individual, sino de agregar estudiantes de similar origen social en la misma escuela (RAVELA, 2007 apud GARCÍA-HUIDOBRO, 2009).

La extensión de la escolarización sin políticas de integración social solo significará nuevas desigualdades, ocultas bajo un mayor nivel de estudios, una escuela que servirá a la reproducción social mejor que nunca, porque tiene más peso económico para la inserción social y laboral.

La proliferación de estrategias de compensación, que suponen una separación del alumnado del grupo normal son las que más proliferan en España (diversificación curricular, planes de acción tutorial, diversos mecanismos de refuerzo escolar...) frente a países como Finlandia, Noruega, Dinamarca e Islandia, donde predominan los métodos de atención individualizada, apoyo del profesorado dentro del aula, prevención temprana de dificultades y la no separación del alumnado para lograr su integración (SAVE THE CHILDREN, 2017).

La ley Orgánica de la mejora Educativa de España (LOMCE) ha significado el aumento de medidas de inequidad, respondiendo al nuevo 
modelo mercantilista de justicia social, como es: la consolidación de itinerarios o ramas a edades cada vez más tempranas, cuando el alumnado puede cambiar todavía su afección por los estudios. Justifica la diferenciación de los estudiantes por sus "talentos", lo que también se realiza a través de la admisión diferenciada por rendimientos, ${ }^{11}$ o con la creación de centros especializados, propuestas contrarias incluso a la OECD.

\subsection{Políticas mercantilistas y liberalizadoras contrarias a la equidad}

El modelo de educación de masas del capitalismo industrial sirvió para sancionar la meritocracia (NOVOA, 2013), pero el nuevo modelo mercantilista de la educación va a clasificar y ordenar según las demandas sociales de empresas y familiares, reforzando la diferenciación de clase en un modelo competitivo y privatizador que busca la satisfacción de los clientes. Ni la misma OECD apuesta por mecanismos de elección de centro y de mercado, aunque muchas de sus propuestas entren en contradicción: "la elección y los mecanismos de mercado asociado que no toman en cuenta las consideraciones de equidad pueden resultar en una mayor segregación de los estudiantes por habilidad, ingreso u origen étnico" (ORGANISATION FOR ECONOMIC CO-OPERATION AND DEVELOPMENT, 2017, p. 9).

Como indica Tedesco (2009), los procesos de gestión educativa (descentralización, autonomía, evaluación e información) transfirieron mayor poder a la demanda, para dar mayor capacidad a los actores locales, las familias y la definición de la oferta educativa. Pero la experiencia ha demostrado que es necesario distinguir entre demanda y necesidad. La demanda está desigualmente distribuida y los requerimientos de un grupo social rápidamente se transforman en necesidad.

La escuela sigue siendo una fiel aliada en la reproducción social y la meta de la educación hacia el mercado de trabajo convierte a la educación en un instrumento del sistema capitalista. El sistema educativo se estratifica en niveles de alfabetización instrumentales para la enseñanza básica, y especia-

11 Se reservan un $20 \%$ los centros especializados para el alumnado con mejores rendimientos. lizada y aplicada para la Formación Profesional, para solo posteriormente proporcionar un conocimiento sobre la estructura de nuestro mundo y no en todos los casos.

La Nueva gestión de los centros educativos está integrada por elementos como el control de la educación a través de la evaluación, modelos de gestión de empresas, una financiación según resultados, o la elección de centros, entre otros. La evaluación se convierte en un elemento clave para el control de los centros, los cuales obtendrán financiación en función de los resultados obtenidos y del número de alumnos que son captados por cada centro.

$\mathrm{Ni}$ contamos con políticas educativas que estén actuando con equidad en las escuelas, ni la educación es ya un ascensor social, marcando la diferencia el capital social y cultural y los recursos extras a la escuela. El fin de la movilidad social ascendente hará que la riqueza se herede aún más. En 2008 el 28\% de los jóvenes que abandonan prematuramente la educación en España provenían del $20 \%$ más desfavorecido (primer quintil), mientras que en 2015 era el 33\%. Hay políticas públicas que igualan las condiciones de partida, pero que igualmente están marcadas por las desigualdades (TEDESCO, 2009).

El problema que se está produciendo con la segregación escolar como consecuencia del crecimiento de la escuelas privadas y de la elección de escuela por parte de las familias, tiene que ver con que la educación y la formación no representa una expectativa directa de inserción laboral.

Para el Banco Mundial (2005) la mejora de los sistemas educativos se hará con propuestas políticas que incluirán el uso eficiente de los recursos educativos y de la organización de los sistemas educativos. Ello se realizará a través de mecanismos de rendición de cuentas y de modelos de gestión eficiente. La financiación sostenible, eficiente y de calidad dentro de los ámbitos prioritarios para el Consejo de Educación de Europea (UNIÓN EUROPEA, 2015) supone: a) modelos de financiación privada; b) políticas basadas en datos evaluados y con seguimiento para que conduzcan a una educación de calidad y eficiente; y c) inversión sostenible basada en los resultados y en el reparto de los costes cuando procede. 
La financiación sostenible y la gestión eficaz acaban con la igualdad, la inclusión, las metodologías innovadoras y la investigación. Las escuelas para mejorar sus resultados solo pueden seleccionar alumnado de alta literacia (aptitudes generadas en niveles socioeconómicos y culturales altos), como realizan los centros privados y cada vez más los públicos, para conseguir un buen desempeño docente en la dinámica competitiva que crean las evaluaciones.
La equidad se formula a través de ideas democráticas y de igualdad, mientas se imponen metodologías instrumentales, ligadas a la calidad educativa, para satisfacer una ideología de mercado que reproduce las clases sociales y las jerarquías. La escuela fortalecerá la selección y clasificación por niveles socio-económicos. Ante la falta de financiación los resultados son una educación pública de bajo coste, con escasos recursos humanos y materiales y el aumento de la privatización.

\section{REFERENCIAS}

ALLIAUD, Andrea. La formación de los docentes. En: ROMERO, C (Comp.). Claves para mejorar la escuela secundaria. Buenos Aires: Noveduc, 2009. p. 117-136.

BALL, Stephen J. What is policy? Texts, trajectories and toolboxes. Discourse: Studies in the Cultural Politics of Education, v. 13, n. 2, p. 10-17, 1993.

BALL, Stephen J.; MAGUIRE, Meg.; BRAUN, Annette. How Schools do Policy. Policy enactments in Secondary Schools. London: Routledge, 2012.

BANCO MUNDIAL. La educación en América Latina y el Caribe. Washington, DC, 1999.

Cerrar la brecha en educación y tecnología. Bogotá, 2005. Disponible en: $<\mathrm{http}: / /$ documentos.bancomun-

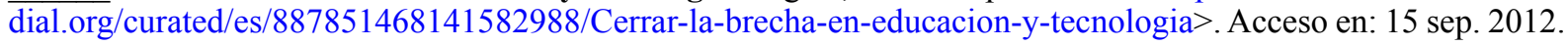

BARBER, Michael; MOURSHED, Mona. Cómo hicieron los sistemas educativos con mejor desempeño del mundo para alcanzar sus objetivos. Buenos Aires: McKinsey \& Company, 2008.

BECK, Ulrich. ¿Qué es la globalización? Falacias del globalismo, respuestas a la globalización. Barcelona: Paidós, 1998.

CARABAÑA, Julio. La inutilidad de PISA para las escuelas. Madrid: Catarata, 2015.

CARNOY, Martin. Economía de la educación. Barcelona: Editorial UOC, 2006.

CONFEDERACIÓN SINDICAL DE COMISIONES OBRERAS - CCOO. El gasto público educativo durante la crisis: evolución por comunidades y financiación del Ministerio de educación para 2018. Madrid: Federación de enseñanza de CCOO, 2018.

COMISIÓN ECONÓMICA PARA AMÉRICA LATINA - CEPAL; ORGANIZACIÓN DE LAS NACIONES UNIDAS PARA LA EDUCACIÓN, LA CIENCIA Y LA CULTURA - UNESCO. Educación y conocimiento: eje de la transformación productiva con equidad. Santiago de Chile: Oficina Regional de Educación de la Unesco para América Latina y Caribe (Orealc), 1992.

Invertir mejor para invertir más. Financiamiento y gestión de la educación en América Latina y el Caribe. Santiago de Chile, 2005. (Serie Seminarios y Conferencias, $\mathrm{n}^{\circ} 43$ ). Disponible en: < http://www.cepal.org/ es/publicaciones/13107-invertir-mejor-invertir-mas-financiamiento-gestion-la-educacion-america-latina $>$. Acceso en: 13 jun. 2008.

DALE, Roger. Globalização e educação: demostrando a existência de uma "cultura educacional comum" ou localizando uma "agenda globalmente estructurada para a educação"? Educação e Sociedade, Campinas, SP, v. 25, n. 87, p. 423-460, 2004. Disponible en: http://www.cedes.unicamp.b2. Acceso en: 03 sep. 2008.

. A Sociologia da Educação e o Estado após a globalização. Educação e Sociedade, Campinas, SP, v. 31, n. 113, p. 1099-1120, 2010.

DE SOUZA, Ângelo Ricardo. A teoria da agenda globalmente estruturada para a educação e sua apropriação pela pesquisa em políticas educacionais. Revista Brasileira de Política e Administração da Educação - RBPAE, v. 32, n. 2, p. 463-485, 2016. 
DUBET, François. Repensar la justicia social. Buenos Aires: S. XXI, 2011.

ESPAÑA. Ley Orgánica no 8, de 9 de diciembre de 2013, para la mejora de la calidad educativa (LOMCE). Agencia Estatal Boletín Oficial del Estado (BOE) de 10 de diciembre de 2013. Madrid, 2013.

EUROPEAN UNION - EU. European Commission. Eurydice Highlights. Key data on teachersad school leaders in Europe. Luxembourg: Publications Office of the European Union, 2013.

Informal Meeting of European Union Education Ministers. Declaration on promoting citizenship and the common values of freedom, tolerance and non-discrimination through education. Paris, 2015. Disponible en: $<\mathrm{http} / /$ ec.europa.eu/dgs/education_culture/repository/education/news/2015/documents/citizenship-education-declaration_en.pdf>. Acceso en: 5 de abr. de 2017.

FALUS, Lucila; GOLDBERG, Mariela. Perfil de los docentes en América Latina. Buenos Aires: Unesco, 2011. FEND, Helmut. La nueva gobernanza de la educación: posibilidades de reforma y riesgos de fracaso. En: THRÖLER, D.; BARBU, R. Los sistemas educativos. Perspectiva histórica, cultural y sociológica. Barcelona: Octaedro, 2012. p. 45-58.

FILMUS, Daniel. (Comp.) Para qué sirve la escuela. Argentina: Editorial Norma, 1994.

GARCÍA-HUIDOBRO, Juan Eduardo. Una nueva meta para la educación en Latinoamérica en el Bicentenario. En: MARCHESI, A.; TEDESCO, J. C.; COLL, C. (Ed.). Calidad, equidad y reformas en la enseñanza. Madrid: OEI, 2009, pp. 19-34.

GIDDENS, Anthony. EI mundo desbocado los efectos de la globalización en nuestras vidas. Madrid: Taurus, 2000. GOROSTIAGA, Jorge M.; TELLO, Cesar G. Globalización y reforma educativa en América Latina: un análisis inter-textual. Revista Brasileira de Educação, v. 16, n. 47, p. 363-388, 2011.

GORTÁZAR, Lucas. Una panorámica de la (in)equidad educativa. 2017. Disponible en: < https://politikon. es/2017/05/11/una-panoramica-de-la-inequidad-educativa/>. Acceso en: 8 sep. 2017.

HIRTT, Nico. Educar y formar bajo la dictadura del mercado de trabajo. Formas de Resistencia y Modos de Educación. Con-ciencia Social, n. 17, p. 39-54, 2013.

INSTITUTO NACIONAL DE EVALUACIÓN EDUCATIVA - INEE. Entrevista a Ismael Sanz: el estudio piloto de la evaluación de $3^{\circ}$ Educación Primaria. 2015. Disponible en: $<$ http://blog.educalab.es/inee/2015/02/23/ entrevista-a-ismael-sanz-el-estudio-piloto-de-la-evaluacion-de-3o-educacion-primaria>. Acceso en: 20 ene. 2015.

LAVAL, C. H.; DARDOT, P. La nueva razón del mundo: ensayo sobre la sociedad neoliberal. Barcelona: Gedisa, 2010.

LLORENS, F. J. Y.; FUENTES, M. M. Calidad total. Fundamentos e implantación. Madrid: Pirâmide, 2000.

LÓPEZ, Nestor. Las metas educativas ante el nuevo panorama social y cultural de América Latina. En: MARCHESI,

A; TEDESCO, J. C,; COLL, C. (Ed.). Calidad, equidad y reformas en la enseñanza. Madrid: OEI, 2009. p. 35-46.

LUBIENSKI, Christopher. Do quasi-markets Foster innovation in education? A comparative perspective. OECD, 2009. Disponible en: <http://www.oecd.org/dataoecd/41/6/43415929.pdf>. Acceso en: 04 jul. 2012.

MARCELO, Carlos (Coord.). Evaluación del desarrollo profesional docente. Barcelona: Editorial Davinci, 2011.

MARTÍN RODRÍGUEZ, Eustaquio. Mejorar el currículum por medio de su evaluación. En: GIMENO SACRISTÁN, J. (Comp.). Saberes e incertidumbres sobre el currículum. Madrid: Morata, 2010. p. 620-636.

MONARCA, Héctor; MANSO, Jesús. Desarrollo profesional docente. Marco para el diseño, seguimiento y evaluación de políticas. Santiago: OEI, 2015.

MOURSHED, Mona; CHIJIOKE, Chinezi; BARBER, Michael. How the world's most improved school systems keep getting better. London: McKinsey \& Company, 2010.

NAVAS QUINTERO, Andrés. La nueva gestión pública. Una herramienta para el cambio. Perspectivas, n. 38, p. 36-38, 2010.

NEAVE, G. Accontability and control. European Journal of Education, v. 15, n. 1, p. 49-60, 1980.

NOVOA, António. La construcción de un espacio educativo europeo: gobernando a través de los datos y la com- 
paración. Revista Española de Educación Comparada, n. 16, p. 23-41, 2010.

Pensar la escuela más allá de la escuela. Con-ciencia Social, n. 17, p. 27-38, 2013.

OLIVIERA, Dalila A. Regulação das políticas educacionais na América Latina e suas consequências para os trabalhadores docentes. Educação e Sociedade, Campinas, SP, v. 26, n. 92, p. 753-775, 2005.

ORGANISATION FOR ECONOMIC CO-OPERATION AND DEVELOPMENT - OECD. Education Policy Outlook 2015: making reforms happen. Paris: OECD Publishing, 2015.

Equity and Quality in Education. Supporting Disadvantaged Students and Schools. Paris: OECD Publishing, 2012. Disponible en: <https://www.oecd.org/education/school/50293148.pdf $>$. Acceso en: 07 ago. 2012.

. Mind the gap: inequity in education. Trends Shaping Education Spotlight 8. Paris: OECD Publishing, 2017. Disponible en: <https://www.oecd.org/edu/ceri/Spotlight8-Inequality.pdf > . Acceso en: 10 oct. 2017. shing, 2009.

Creating effective teaching and learning environments: first results from TALIS. Paris: OECD Publi-

Results: an international perspective on teaching and learning. Paris: OECD Publishing, 2013. Disponible en: <http://dx.doi.org/10.1787/9789264196261-en>. Acceso en: 07 ago, 2012.

ORGANIZACIÓN DE ESTADOS IBEROAMERICANOS - OEI. Metas 2021: la educación que queremos para la generación de los Bicentenarios. Documento final. Madrid: OEI, 2010.

ORGANIZACIÓN DE LAS NACIONES UNIDAS PARA LA EDUCACIÓN, LA CIENCIA Y LA CULTURA - UNESCO. Sistema de Información de Tendencias Educativas en América Latina (SITEAL). Informe sobre tendencias sociales y educativas en América Latina. Buenos Aires, 2007. Disponible en: <http://www.siteal. iipe-oei.org/informetendencias/informetendencias.asp>. Acceso en: 12 feb. 2010.

Sistema de Información de Tendencias Educativas en América Latina (SITEAL). Informe sobre tendencias sociales y educativas en América Latina. Buenos Aires, 2008. Disponible en: < http://www.siteal.iipe-oei. org>. Acceso en: 12 feb. 2010.

World Education Forum. The Dakar framework for action. Paris, 2000.

La educación para todos 2000-2015: logros y desafíos. Informe de seguimiento de la ETP en el mundo. UNESCO, 2015. Disponible en: <http://unesdoc.unesco.org/images/0023/002325/232565s.pdf>. Acceso en: 07 ago. 2012.

OXFAM INTERMON. La trampa de la austeridad: el verdadero coste de la desigualdad en Europa. Oxford, 2013. Disponible en: <http://www.oxfamintermon.org/es/documentos/11/09/13/trampa-de-austeridad >. Acceso en: 07 ago. 2017.

Informe de Oxfam. Una economía para el 99\%. Es hora de construir una economía más humana y justa al servicio de las personas. Enero, 2017. Disponible en: $<\mathrm{https} / / \mathrm{d} 1 \mathrm{tn} 3 \mathrm{vj} 7 \mathrm{xz} 9 \mathrm{fdh}$.cloudfront.net/s3fs-public/file attachments/bp-economy-for-99-percent-160117-es.pdf>. Acceso en: 07 ago. 2017.

PINI, Mónica. Análisis crítico del discurso: la mercantilización de la educación pública en España y la Unión Europea. Revista de Educación, v. 1, n. 1, p. 77-96, 2010.

POGGI, Margarita. Una radiografía de los sistemas educativos de América Latina. Desafíos para las políticas educativas. Pensamiento Iberoamericano, n. 7, p. 3-25, 2010.

RAVIT, Diane. The death and life of the great american school system: how testing and choice are undermining education. New York: Basic Books, 2010.

Unless teachers write the tests, they won't improve anything. The New Republic, 27 sept. 2013.

ROGERO-GARCÍA, Julio. El informe PISA, la segregación escolar y la Luna. 2017. Disponible en: <http:// agendapublica.elperiodico.com/el-informe-pisa-la-segregacion-escolar-y-la-luna/>. Acceso en: 8 sep. 2017.

ROSANVALLON, Pierre. La sociedad de los iguales. Barcelona: RBA, 2012.

SACHS, J. El precio de la civilización. Barcelona: Galaxia Gutenberg, 2012.

SAFOCARDA, Fernanda; MIGLIAVACA, Adriana; JAIMOVICH, Analía. Trabajo docente y reformas neolibe- 
rales: debates en la Argentina de los 90. En: FELDFEBER, M.; ANDRADE OLIVEIRA, D. (Comp.). Políticas educativas y trabajo docente. Nuevas regulaciones ¿Nuevos sujetos? Buenos Aires: Noveduc, 2006. p. 205-220.

SAVE THE CHILDREN. Desheredados. Desigualdad infantil, igualdad de oportunidades y políticas públicas en España. 2017. Disponible en: <https://www.savethechildren.es/sites/default/files/imce/docs/desheredados_pobreza_infantil_informe.pdf $>$. Acceso en: 8 abr. 2018.

SENNETT, Richard. La cultura del nuevo capitalismo. Barcelona: Anagrama, 2006.

TEACHING AND LEARNING INTERNATIONAL SURVEY - TALIS. Talis - main findings from the survey and implications for education and training policies in Europe. Paris: OCDE, 2013.

TEDESCO, Juan Carlos. ¿Son posibles las teorías de la subjetividad? En: TENTI, E. (Comp.). Nuevos temas en la agenda de la política educativa. Buenos Aires: Siglo XXI, 2008. p. 53-64.

Los temas de la agenda sobre gobierno y dirección de los sistemas educativos en América Latina. En: MARCHESI, A.; TEDESCO, J. C.; COLL, C. (Ed.). Calidad, equidad y reformas en la enseñanza. Madrid: OEI, 2009. p. 77-86.

Diez notas sobre los sistemas de evaluación de los aprendizajes. Lima: Oficina Internacional de Educación (OIE) de la Unesco, 2016. (Serie Cuestiones fundamentales y actuales del currículo, el aprendizaje y la evaluación, $\left.n^{\circ} 5\right)$.

TENTI FANFANI, Emilio. La escuela y la cuestión social. Buenos Aires: Siglo Veintiuno, 2007.

TERIGI, Flavia. Los saberes docentes: formación, elaboración en la experiencia e investigación. Buenos Aires: Santillana, 2012.

UNIÓN EUROPEA - UE. Consejo de la Unión Europea. Nuevas prioridades para la cooperación europea en educación y formación. Informe conjunto de la Comisión y los Estados miembros. Diario Oficial de la Unión Europea, 15 dec. 2015. Número 417, p. 25. Disponible en: <http://eur-lex.europa.eu/legal-content/ES/TXT/PDF/?uri=OJ:JOC_2015_417_R_0004\&from=ES $>$. Acceso en: 3 mar. 2017.

. Consejo de la Unión Europea. Educación y Formación 2010. Urgen las reformas para coronar con éxito la estrategia de Lisboa. Bruselas, 2004. Disponible en: $<$ http://register.consilium.europa.eu/doc/srv?l=ES\&f=ST\%20 6905\%202004\%20INIT>. Acceso en: 10 mar. 2017.

Consejo de la Unión Europea. Conclusiones del Consejo de 12 de mayo de 2009 sobre un marco estratégico para la cooperación europea en el ámbito de la educación y la formación (ET 2020). Diario Oficial de la Unión Europea, 28 mayo 2009. Número 119, p. 2. Disponible en: <http://eur-lex.europa.eu/LexUriServ/LexUriServ. do?uri=OJ:C:2009:119:0002:0010:ES:PDF>. Acceso en: 10 ago. 2010.

VAN ZANEN, Agnes. El fin de la meritocracia? Un análisis de los cambios recientes en las relaciones de la escuela con el sistema económico, político y social. En: TENTI FANFANI, E. (Comp.). Nuevos temas en la agenda de política educativa. Madrid: Siglo XXI, 2008. p. 173-192.

VERGER, Antony; BONAL, Xavier. La emergencia de las alianzas público-privado en la agenda educativa global: nuevos retos para la investigación educativa. Profesorado. Revista de Currículum y Profesorado, v. 16, n. 3, p. 11-29, 2012.

VERGER, Antony; MOSCHETTI, Maura; FONDVILLA, Clara. La privatización educativa en América Latina: una cartografía de políticas, tendencias y trayectorias. Barcelona: Internacional de la Educación, 2017. Disponible en: <https://download.ei-ie.org/Docs/WebDepot/Privatizacion\%201-Abril.pdf>. Acceso en: 08 abr. 2018.

VIÑAO, Antonio. El modelo neoconservador de gobernanza escolar. Principios, estrategias y consecuencias en España. En: COLLET, J.; TORT, A. (Coord.). La gobernanza escolar democrática. Madrid: Morata, 2016. p. 41-64.

WEBER, Max. Economía y sociedad. México: Fondo de Cultura Económico, 2002. 